Fecha de recepción: diciembre 2018 Fecha de aceptación: marzo 2019 Versión final: junio 2019

\section{Mujeres pioneras en el cine experimental y el video arte argentino}

Eleonora Vallazza *

Resumen: El presente ensayo indagará sobre el rol protagónico de mujeres realizadoras, programadoras y curadoras de cine experimental y video arte argentino. Se analizarán los trabajos tanto en la realización de obra audiovisual como también en sus facetas de programadoras de salas, museos, centros culturales, que han dedicado espacios a la difusión del audiovisual experimental argentino.

Si bien se nombrarán varios casos, se analizarán puntualmente los momentos históricos de gestación y consolidación del cine experimental y video arte en Argentina. Un punto en común, más allá de los diversos contextos políticos y culturales, es el activismo de estas realizadoras en relación a los derechos de las mujeres en el medio audiovisual.

Los nombres y casos de mujeres desatacadas en ambos son los siguientes.

Marie-Louise Alemann, una de las pioneras del cine experimental, formó el "Grupo Cine Experimental Argentino" en la sede del instituto Goethe y estuvo a cargo de la programación de la Cinemateca entre 1979 y 1985, espacio donde se podían ver y debatir los films de Rainer Werner Fassbinder, Alexander Kluge, Edgar Reitz o Wim Wenders. Nació en Alemania en 1927 y se radicó en el país en 1949. Se desempeñó como fotógrafa, periodista, actriz teatral y artista plástica y hacia 1967 -cuando la dictadura militar de Juan Carlos Onganía comenzaba a cercar al Instituto Di Tella- participó junto a sus amigos Walter Mejía y Narcisa Hirsch de un happening en la puerta de la sala donde se estrenaba Blow Up, de Michelangelo Antonioni. Aquella intervención en la vía pública fue documentada por Raymundo Gleyzer, en lo que se considera fue una de los pocas coincidencias entre lo que por entonces eran las vanguardias políticas y estéticas.

Narcisa Hirsch, pionera del cine experimental argentino, participó del mismo grupo. El cine "es solo luz proyectada, movimiento puro" sostenía vehementemente Narcisa Hirsch en una entrevista (Paparella, 1995: 34). Retomando una de las premisas básicas del modernismo pictórico. Hirsch proponía concentrarse en la propia esfera de materiales y significación del cine como medio; en su "esencia". El cine experimental presentaba su propia materia, construía su objeto sin ningún tipo de intención narrativa o diegética.

Por el lado del video arte, en otro contexto histórico y cultural, fuertemente ligado a los avances técnicos y a la masividad de las cámaras videograbadoras, analizaremos el caso de Graciela Taquini. En relación a la figura de Graciela Taquini, se puede mencionar que ha sido y continúa siéndolo hasta hoy, una figura clave en la difusión y exhibición del video arte argentino. Es una artista y curadora argentina que ha desarrollado la mayor parte de su producción artística en el área del video experimental monocanal. Sus obras han recibido diferentes premios, entre ellos el Premio de la Asociación de Críticos de Arte de la Argentina al mejor guion, el Primer Premio del Festival Videobrasil, y en 2005 el Premio a la Acción Multimedia, Asociación Argentina de Críticos de Arte. Ha sido apodada "la 
tía del videoarte argentino" por su temprana participación e interés en dicha disciplina. En 2012 recibió la Premio Konex de Platino en Video Arte. Es miembro de número de la Academia Nacional de Bellas Artes.

Finalmente, y en relación al uso de los nuevos medios, se reflexiona sobre un grupo de mujeres realizadoras y gestoras culturales dedicadas al cine y video experimental, se mencionará el caso de AREA Asociación de realizadores experimentales audiovisuales. Si bien no es un grupo exclusivamente femenino, cuenta con una comisión de género en el que la problemática de la mujer en el cine y en el audiovisual experimental es ampliamente abordada, en un contexto contemporáneo.

Palabras clave: pioneras- cine experimental - video arte- realización- gestión culturalGoethe- tecnología- nuevos medios- feminismos.

[Resúmenes en inglés y portugués en las páginas 89 - 91]

${ }^{(*)}$ Licenciada y Profesora en Artes (UBA). Especialista Superior en Gestión Cultural (Fundación Konex). Docente e investigadora en artes audiovisuales. Publicó en revistas académicas y en medios gráficos periodísticos. Trabaja en gestión de eventos culturales, y en festivales internacionales de cine como BAFICI y SANFICI (Colombia).

El presente ensayo, parte de la elaboración de una hipótesis de investigación, realizada dentro del marco del Programa de Investigación de la Facultad de Diseño y Comunicación de la UP (Universidad de Palermo). La misma afirmaba que:

El audiovisual experimental argentino, desde sus comienzos hasta la actualidad, ha sido producido al margen de los códigos y convenciones del cine narrativo de ficción, tanto comercial como independiente. La radicalidad del lenguaje y de los modos de producción propios del audiovisual experimental argentino, generan un impacto directo en los criterios y espacios de circulación del mismo, escapando así a políticas culturales oficiales y dependiendo exclusivamente de voluntades individuales, personales y en algunos casos institucionales, para dar visibilidad en espacios de difusión cultural. (2018)

Estas voluntades individuales, y en algunos casos, voluntades institucionales circunstanciales, fueron representadas por mujeres: investigadoras, realizadoras y curadoras que en distintos contextos históricos, culturales y políticos, han representado una actitud de resistencia frente a la hegemonía de programadores ligados al cine narrativo o documental, o de instituciones culturales que históricamente han sido dirigidas por hombres. 
Marie-Louise Alemann, una de las pioneras del cine experimental, formó el "Grupo Cine Experimental Argentino" en la sede del instituto y estuvo a cargo de la programación de la Cinemateca entre 1979 y 1985, espacio donde se podían ver y debatir los films de Rainer Werner Fassbinder, Alexander Kluge, Edgar Reitz o Win Wenders. Nació en Alemania en 1927 y se radicó en el país en 1949. Se desempeñó como fotógrafa, periodista, actriz teatral y artista plástica y hacia 1967 -cuando la dictadura militar de Juan Carlos Onganía comenzaba a cercar al Instituto Di Tella- participó junto a sus amigos Walter Mejía y Narcisa Hirsch de un happening en la puerta de la sala donde se estrenaba Blow Up, de Michelangelo Antonioni. Aquella intervención en la vía pública fue documentada por Raymundo Gleyzer, en lo que se considera fue una de los pocas coincidencias entre lo que por entonces eran las vanguardias políticas y estéticas.

Luego de sus primeras experiencias en el formato Súper 8mm, Marie-Louise, en 1972 se convirtió en una de las fundadoras del llamado Grupo Cine Experimental Argentino, junto a Claudio Caldini, Juan Villola, Juan José Mugni, Horacio Vallereggio, Adrián Tubio y Narcisa Hirsch. Pero fueron mejor conocidos como el Grupo Goethe, porque fue el Goethe-Institut el que les cedió un espacio para sus reuniones y luego, con la inauguración de su magnífico auditorio (que al día de hoy permanece cerrado), también para la difusión de sus obras.

A partir de entonces, Marie-Louise, gracias a sus frecuentes viajes, se convirtió en una interlocutora privilegiada del joven cine alemán de esa época. Entre 1979 y 1985, cuando tuvo a su cargo la programación cinematográfica del Goethe. Nekes y Schroeter ofrecieron seminarios sobre cine experimental y el de Schroeter (amenazado por la última dictadura militar) produjo como resultado el film colectivo De la Argentina (1983-1985). El mismo tuvo su estreno recién llegó a verse en el país en 2013, para la retrospectiva Schroeter exhibida en la Sala Leopoldo Lugones. (Teatro San Martín).

La escena experimental porteña estuvo conformada por dos grandes grupos de cineastas, de diversas procedencias, tradiciones y concepciones del quehacer cinematográfico: el cine experimental de Narcisa Hirsch, Claudio Caldini, Marie-Louise Alemann, Horacio Valleregio, Silvestre Byrón, entre otros (algunos de los cuales conformarían en la década del 70 lo que se conoció como "Grupo Goethe"), y el cine contestatario, provocador e irreverente de Alberto Fischerman, Julio Ludueña, Miguel Bejo, Bebe Kamin, Edgardo Kleinman y Edgardo Cozarinsky.

Como sostiene Denegri (2012), la institucionalización del grupo, además de otorgarles un lugar físico para la proyección de sus obras logró conformar una “identidad común” entre los cineastas, lo que propició también la realización de un extenso corpus de obras por un largo período de tiempo.

Alemann, fue fotógrafa, periodista y artista plástica. Su figura y su obra fueron rescatadas en el filme "Butoh", de Constanza Sanz Palacios, que fue exhibido en el Bafici (2013, Buenos Aires Festival Internacional de Cine Independiente) como un retrato de esta contemporánea de otros artistas experimentales como Narcisa Hirsch, Walter Mejía y Claudio Caldini, pertenecientes a una vanguardia de cineastas que a partir de los 60 exploraron formas de representación abstractas. Su relación con el Instituto Goethe perduró a lo largo del tiempo. Entre 1979 y 1985 tuvo a su cargo la programación de las exhibiciones cinematográficas, donde incluyó obras de creadores alemanes de la década de 1970, como Rainer Werner Fassbinder, Werner Nekes, Werner Herzog y Werner Schroeter. 
Según la autora Toro, Karen Alejandra (2012, Creación y Producción en Diseño y Comunicación No48) Marie Louise Alemann tiene una prolífica obra cinematográfica con aproximadamente 30 cortometrajes en su filmografía que se realizaron entre 1967 hasta 1985, la mayoría de los cuales fueron realizados en $8 \mathrm{~mm}$. Sólo algunos pocos de los primeros cortos fueron hechos en $16 \mathrm{~mm}$. "A pesar de esto, hay algunas cuestiones visibles en la obra de Marie Louise que es preciso nombrar, ya que resultan llamativas de su obra: 1) hay una autorreferencialidad evidente en la mayoría de sus cortometrajes, ya sea como Marie Louise misma, como mujer y como madre, 2) el sentir del paso del tiempo, 3) la familia y las presiones sociales y 4) una especie de simbolismo arcaico" (Toro, 2012).

Continuando con las reflexiones de Toro, otras cuestiones evidentes en la obra de Marie Louise, es por ejemplo, la presencia de muy poca información dentro del cuadro. De esta forma prima el simbolismo en su obra, por sobre el contenido narrativo o puramente abstracto: playas desiertas, bosques, ríos, etc. (jamás se observa ninguna referencia a lo urbano) y en la música y sonidos que acompañan los films. También podemos observar que otras veces el sonido es distorsionado, las voces son aceleradas o ralentizadas, etc. Asimismo, cabe señalar que existía una vinculación bastante fuerte de alguna gente del Grupo cine experimental argentino con el movimiento rockero de la época. Finalmente, en relación al análisis de la autora mencionada, se concluye que en la obra de Marie Louise Alemann, lo que resulta interesante es su manera de poner en manifiesto ese simbolismo sencillo en toda su obra, experimentar consigo misma inscribiéndose como sujeto de enunciación en la imagen. Muchas veces reflejó y exploró cuestiones íntimas (tomas en las que aparece ella misma y su hija Katja Alemann) para de cierta forma, interpelar al espectador en su propia intimidad.

Lo íntimo, lo personal hecho público desde la experimentalidad, constituye la esencia de la obra de esta pionera del cine experimental en Argentina. Otra de las autoras y realizadoras vinculadas al Grupo Goethe fue Narcisa Hirsch.

Narcisa Hirsch (1928), cineasta experimental que en sus obras indaga, al igual que otros artistas de la época, en la naturaleza del sujeto femenino. En general sus producciones exploran el mundo de la mujer de los años 60 y 70, cuya identidad está en construcción, ocupando diversos roles y participando en los diferentes ámbitos de la vida cultural. Obras como Taller (1975) o El mito de Narciso (1974-2005) tratan sobre lo femenino y el surgimiento del feminismo en la década del sesenta en Buenos Aires, que proponía una toma de conciencia sobre la situación social y cultural de la mujer. En su obra se entrecruzan lo experimental, la política, el arte y su interés por los derechos de la mujer y el lugar que debe ocupar en la sociedad. Sus films de carácter cercano al surrealismo, son como collages donde se mezclan citas, fotografías, e imágenes fílmicas.

La artista inició su carrera en los años 50 en un contexto en el cual en Buenos Aires comenzaban a manifestarse las nuevas vanguardias artísticas, entre los espacios donde se desarrollaban estas experiencias estaban el Instituto de Arte Moderno, el Torcuato Di Tella y la galería Lirolay donde la artista hizo varias muestras de pinturas y objetos.

Desde el inicio su cine fue experimental, un tipo de cine que tenía sus orígenes en las vanguardias cinematográficas de los años 30 con Buñuel y Dalí en España y con Hans Richter en la "Bauhaus" en Alemania. Este cine tuvo un impasse durante la segunda guerra mundial, y volvió con más fuerza en los años 50 y 60 en Estados Unidos, de la mano de Jonas Mekas. 
"Experimental se entiende aquí como la insubordinación respecto del relato lineal, como la intervención constante en la visibilidad de la imagen, como el corte y el montaje de planos y secuencias acumulados con ciertos ritmos, como la colisión entre lo abstracto y lo narrativo tanto en la imagen como en el sonido." (Giunta, 2013)

Los films se hacían sin guion ni presupuesto, en el contexto de gente que trabajaba "intuitivamente, entre corazonadas de plásticos, poetas, actores y bailarines con ganas de "hacer cosas" Byrón destaca la búsqueda de formas abiertas, de relaciones metonímicas; la huida de la masificación y de las instituciones. El cine como generador de imágenes opcionales. Lo define como un Cuarto Cine "que busca lo raro y lo oculto, el misterio y lo desconocido" alejado, por lo tanto, del manifiesto de 1969 de Solanas y Gettino, "Hacia un tercer cine", y diferente tanto del cine de Hollywood, como del cine de autor europeo. Un cine que busca generar imágenes opcionales, indaga en lo irracional y lo amoral, que no tiene liderazgos, ni cuenta con la financiación de fundaciones, partidos o asociaciones. Un cine sin prensa y sin industria. Fueron, según Byrón, obras producidas en y contra un contexto político: "Aquellos fueron, simultáneamente, años de represión, militarismo y violencia política. Únicamente el público apoyó al movimiento. Exponiéndose al autoritarismo dominante. Aquellas imágenes, contestatarias y plenas de ese irracionalismo amoral, iban reñidas con las recomendaciones del "ser nacional” (Byrón “Arte y rebelión”).

\section{Obras destacadas}

\section{La marabunta, 1967}

"Marabunta muestra el proceso de armado en su taller de un inmenso esqueleto de yeso, de tres metros de largo, que el 31 de octubre de 1967 se presenta en el teatro Coliseo. Dispuesto sobre una mesa cubierta con un mantel a cuadros, completamente cubierto con naranjas, bananas, sándwiches y con palomas vivas en su interior, el "cuerpo" (femenino) se presenta para que el público lo devore hasta dejar nuevamente expuestos sus huesos." (Andrea Giunta, 2013)

La performance tiene lugar en la puerta del teatro Coliseo, donde se presentaba Blow up (Deseo de una mañana de verano) de Michelangelo Antonioni. El nombre de la obra hace referencia a una clase de hormiga que se mueve en grandes masas en busca de alimento devorando todo lo que encuentran a su paso. La autora cuenta que:

"la obra que implicó un gran despliegue, con música electrónica, cotorras vivas en el cráneo, palomas pintadas con colores fosforescentes en el vientre. Cuatro docenas de bananas le caían de la cabeza y sándwiches, tortas y todo tipo de comida revestían el cuerpo. Para filmar el evento, Aldo Sessa, entonces director de Laboratorios Alex, me recomendó a un muchacho para que oficiara de cameraman y filmara el proyecto, y ese muchacho era Raymundo Gleyzer. Después edi- 
tamos juntos ese material y ahí me empecé a entusiasmar con el cine, a partir de la edición de ese hecho cinematográfico. Fue entonces cuando empecé a filmar."

La filmación muestra cómo el público come desaforadamente y se lleva la comida que puede en sus carteras y entre sus ropas, el público se asimila así a hormigas voraces, otorgándole al evento un carácter violento y a la vez grotesco, en el que gente bien vestida se abalanza sobre la comida.

Dice Graciela Taquini (2008) sobre esta obra:

"Narcisa era una de esas asiduas espectadoras del nuevo cine europeo. Al planificar el happening, siente la necesidad de registrar el efímero acontecimiento. Aspira captar ese evento único y singular donde hay un público participativo que interactúa con la obra. "Marabunta" consiste en una gran escultura de un esqueleto cubierto de comida, donde las hormigas gigantes eran los propios espectadores. Una metáfora sobre la antropofagia"

\section{Taller (o Workshop), 1975}

En este corto minimalista, la artista realiza una suerte de reflexión entre lo público y la intimidad que caracteriza los retratos, retratos que en realidad nunca aparecen sino que son sugeridos por las imágenes y la narración de la cineasta.

"El plano secuencia que compone al film, fijo durante los diez minutos de duración, registra una pared del taller-estudio de Hirsch mediante un plano medio que hace foco sobre un puñado de fotografías y recortes pegados en la pared blanca. Más allá de los fundidos al comienzo y al final del plano, y de ciertas variaciones lumínicas que resultan en pequeños balbuceos cromáticos, el film presenta una única e inmutable imagen". (Marin 2010, p. 23) El corto muestra una de las paredes del taller, y durante el resto del film la voz en off de la propia Hirsch, describe los objetos del taller que la imagen muestra, hasta llegar nuevamente a las fotografías y recortes que muestra el encuadre. La detallada descripción que el film proporciona del taller configura un archivo de objetos y fotografías que aparecen en películas anteriores y posteriores.

El corto comienza describiendo la fotografía en el centro del encuadre del balneario chileno de Pucatrihue, donde Hirsch solía vacacionar. Muestra un espacio interior donde puede verse una cama y una mesa pequeña, y una ventana que permite ver el Pacífico. Debajo, muestra la foto de un río de Bariloche, lugar en el que pasa el que Hirsch pasa el verano. A la derecha un gorila albino. Arriba las fotos de los hijos de Narcisa dentro de una antigua bañera. En el ángulo inferior a la derecha se observa una lámpara naranja, como una gran bola, típica de los años 60 .

\section{El mito de Narciso (1974-2005)}

Un film que la artista inicia a mediados de los años setenta, donde vemos rostros de mujeres que miran a la cámara en silencio, y prácticamente sin realizar movimiento alguno 
mientras hablan de sí mismas frente a su imagen, de lo que les sucede al ver ese rostro ante el cual parecen sentirse extrañas. "Las descripciones reponen referencias subjetivas, sentimientos frente a la propia imagen que no se relacionan con lo que vemos. No narran una biografía ni un episodio en esa vida. Nos proponen volver sensible el impacto de encontrarse extraño frente al propio rostro. Al mismo tiempo, actualizan aspectos de los discursos sobre la mujer, sobre lo femenino y de la inscripción del feminismo a comienzos de los años sesenta en Buenos Aires. Fundamentalmente, aquellos que se articulaban a partir de los grupos de concienciación, característicos de la segunda ola del feminismo, que buscaban producir 'conciencia de género', es decir, el proceso de adquisición de una conciencia vinculado a la situación social y cultural de la mujer." (Giunta, 2013)

Estas primeras filmaciones fueron hechas en blanco y negro, y Narcisa agregó luego filmaciones en color en 1979 y en 2005, año en que se editó el video. En los tres films aparece la propia artista, esto hace que podamos ver en el film una suerte de trabajo autobiográfico. Como mencionamos previamente, el audiovisual experimental tampoco se limitó al soporte fílmico. Con los avances tecnológicos y el desarrollo de las cámaras con cinta magnética como las videograbadoras, se desarrolló dentro del campo cultural argentino, el video arte. En este punto analizaremos el caso de Graciela Taquini.

En relación a la figura de Graciela Taquini, se puede mencionar que ha sido y continúa siéndolo hasta hoy, una figura clave en la difusión y exhibición del video arte argentino. Es una artista y curadora argentina que ha desarrollado la mayor parte de su producción artística en el área del video experimental monocanal. Sus obras han recibido diferentes premios, entre ellos el Premio de la Asociación de Críticos de Arte de la Argentina al mejor guion, el Primer Premio del Festival Videobrasil, y en 2005 el Premio a la Acción Multimedia, Asociación Argentina de Críticos de Arte. Ha sido apodada "la tía del videoarte argentino" por su temprana participación e interés en dicha disciplina. En 2012 recibió la Premio Konex de Platino en Video Arte. Es miembro de número de la Academia Nacional de Bellas Artes.

La curaduría como práctica profesional se consolidó en Buenos Aires durante la década del noventa en el marco de un proceso más amplio de institucionalización del arte que impactó en todos los niveles del campo cultural. Estos cambios estructurales modificaron sustancialmente las dinámicas del arte contemporáneo reconfigurando el rol del mercado con la incorporación de nuevos compradores y coleccionistas de arte argentino enfocados en la producción más reciente, a través de nuevas inversiones de capital privado que permitió la creación de nuevos espacios de arte por efecto de la convertibilidad, por medio de la reconfiguración de diferentes agentes del campo como curadores, críticos de arte y gestores culturales.

En 1999 se hizo en el Centro Cultural Recoleta una mega muestra llamada Siglo XX. Arte y Cultura en la que Taquini realizó un programa de vídeo de autor en VHS, dividido en diferentes secciones temáticas. En ese momento encontró constantes como la conflictiva relación del videoarte con su "madre", la televisión. Lo denominó con un slogan de la época, "VT no es TV", video tape no es televisión.

Rodrigo Alonso y Taquini realizaron la curaduría de la muestra "Resplandores, Poéticas analógicas y digitales", en agosto de 2007, también en el Centro Cultural Recoleta de Buenos Aires. En esta exposición, donde participaron más de ciento cincuenta artistas argentinos y 
latinoamericanos, realizaron una selección de obras que dieran cuenta de las relaciones entre el arte y la tecnología, eligiendo obras de vídeo expandido así como también programas monocanal argentinos y latinoamericanos. Sumaron propuestas que apuntaban a experiencias más amplias, a lo interactivo, la robótica, los usos de Internet, etc.

El núcleo temático introductorio subrayaba los antecedentes del vídeo no sólo como cita, sino como apropiación. La muestra se abría y cerraba con obras lumínicas, a manera de una metáfora curatorial acerca del principio binario del encendido y el apagado. El cuerpo, y el paisaje volvían a tener presencia como categorías y se agregaba un núcleo referido a lo doméstico, los interiores. Se podría pensar que los sacudones del post menemismo abrían la necesidad de un imaginario sobre lo privado ante tanto caos institucional. (Taquini, 2008)

La autora y pionera curadora del video arte en Argentina Graciela Taquini, reflexiona sobre el impacto de la tecnología digital en el ámbito de la circulación y exhibición del audiovisual experimental.

“Qué sentido tiene en la era de Youtube programar vídeos en espacios culturales, en el espacio públicos, en circuitos no tradicionales? La creación digital es un lenguaje que no está sometido a la tiranía de los formatos. Un espacio de resistencia, acicateado por la tiranía de un pésimo y frágil soporte como el DVD. Cada vez que se muestra o se intercambia experiencias se fundan vínculos para una estética relacional, un punto de encuentro, de debate e intercambio, un desesperado intento ante tanto bombardeo visual de apelación que quiere romper con la indiferencia y capturar al potencial espectador. Como pocos lenguajes contemporáneos, el vídeo monocanal pierde territorialidad a la vez que se desinstitucionaliza, ya que en su condición binaria, digital, viaja nómada en formatos de unos y ceros a lugares insospechados. Esto podría vislumbrar el fin de las mediatecas, la obsolescencia de los comisarios, la desmaterialización de la información, la crisis de las instituciones de arte y la apertura de nuevos circuitos." (Taquini, 2008)

Finalmente, y en relación al uso de los nuevos medios, y espacios dentro de la academia, se reflexiona sobre dos casos. Por un lado sobre un grupo de mujeres realizadoras y gestoras culturales dedicadas al cine y video experimental, se mencionará el caso de AREA Asociación de Realizadores Experimentales Audiovisuales. Por otro, sobre la Comisión de Experimentación Audiovisual de ASAECA. Espacio fundamental, en el ámbito de la difusión y circulación de audiovisual experimental en Argentina, es el generado por la Comisión de Experimentación, su coordinadora es Brenda Salama (Universidad de Buenos Aires), y está integrada por investigadores y realizadores audiovisuales de Latinoamérica. Con el propósito de investigar, proyectar y difundir cine y video experimental argentino, la Comisión de Experimentación Audiovisual, formada en diciembre de 2011, realizó un ciclo de cine experimental en el Kino Palais (Ciudad de Buenos Aires, 2012), que incluyó homenajes a Narcisa Hirsch, Marie Louise Alemann y Graciela Taquini, iniciadoras de un legado audiovisual en nuestro país. En 2013, el ciclo continuó en la Casa de la Cultura 
del Fondo Nacional de las Artes. Las discusiones y reflexiones sobre la experimentación audiovisual se han llevado a cabo en reuniones, entrevistas, textos académicos y otros formatos, como el dossier: “¿Qué es lo experimental del cine experimental?”, publicado en la revista Imagofagia (abril de 2014) y el libro Poéticas del movimiento (2015). Los objetivos generales y específicos son:

- Investigar, proyectar, visibilizar y difundir el cine y el video experimental argentino y latinoamericano.

- Promover el intercambio entre realizadores/as, investigadores/as y el público en general en torno al cine expandido, las instalaciones audiovisuales y el experimentalismo audiovisual fílmico y digital.

- Crear y fortalecer lazos con festivales de cine, ciclos especializados y eventos académicos (jornadas, charlas, seminarios y simposios) relacionados con el campo de la experimentación en cine y video, así como con espacios expositivos del arte contemporáneo.

La Asociación de Realizadores Experimentales Audiovisuales AREA desde 2017 reúne a decenas de realizadores que utilizan las herramientas de cine y video para investigar las posibilidades de creación narrativas, estéticas y técnicas que ofrece la experimentación audiovisual, tanto digital como analógica y fotoquímica.

Entre sus objetivos se encuentra la organización para la defensa de los intereses y el desarrollo de los derechos de los artistas audiovisuales, así como la visibilización a nivel nacional e internacional de la existencia en la Argentina de una escena cada vez más rica y nutrida de cineastas y videastas experimentales.

Pero también -y principalmente- se propone la creación de un espacio común de reflexión teórico-práctico, divulgación, producción de nuevas obras e intercambio de conocimientos, experiencias y equipos de realización, fortaleciendo los lazos dentro del terreno de la experimentación audiovisual.

Dentro de las últimas programaciones de AREA, se destaca la muestra "Eunuch Dreams" una amplia y atractiva muestra de cine experimental argentino contemporáneo que se llevará a donde se vieron un total de 38 películas de largo y cortometraje realizadas por 18 directores argentinos y otros extranjeros que viven y trabajan en la ciudad de Buenos Aires. La muestra fue curada por el realizador estadounidense radicado en Buenos Aires Jeff Zorrilla y su colega japonés Shotaro Ikeda En la misma se destaca una amplia presencia de realizadoras. La muestra está compuesta por cinco programas, entre ellos el estreno de la película colectiva argentina filmada en Súper 8 milímetros "The Sound We See Buenos Aires", una sinfonía urbana que registra el ritmo vital en distintos barrios de la capital argentina. En los cortos programados, se observa una pulsión hacia el cine experimental y la abstracción, a partir del uso de diferentes recursos (cuadro a cuadro, sobreimpresiones, intervenciones físicas en el celuloide, uso de máscaras) en casi todas las etapas de la realización, desde el registro de la imagen, el revelado, el montaje y su posterior proyección. Las realizadoras experimentales contemporáneas, que formaron parte de esta programación en Japón fueron: Fabiana Gallegos, Melisa Aller, Marto Álvarez; Macarena Cordiviola, Clara Frías y Azucena Losana. 
Gabriela Golder, es otra curadora contemporánea fundamental en el ámbito de la imagen experimental, ya que junto a Andrés Denegri, desde hace varios años, han programado el ciclo "El cine es otra cosa" en el Museo de Arte Moderno de Buenos Aires. Como también han sido los responsables de la dirección y curaduría de la BIM (Bienal de Imagen en Movimiento) junto a la UNTREF (Universidad Nacional Tres de Febrero).

A modo de conclusión, podemos afirmar que la presencia femenina en el ámbito del cine ha sido muy desproporcionada en todas las áreas: producción, dirección, técnica, etc. Sin embargo, esa falta de igualdad dada en el ámbito del cine narrativo, documental o publicitario, se encuentra inversa en el de la experimentación audiovisual. La falta de parámetros rígidos para la calificación de estos films, como la estructura en constante transformación de su propio lenguaje, habilitan espacios alternativos de producción y circulación. En donde la mujer, como grupo minoritario, encuentra poca resistencia de las políticas culturales hegemónicas. La experimentación libera al lenguaje de sus propias reglas, pero también libera las barreras y limitaciones de género, impuestas por el lenguaje audiovisual dominante.

\section{Lista de Referencias Bibliográficas}

Giunta, A. (2013), "Narcisa Hirsch. Portraits" en Alternativas; vol. 1 p. 1 - 19, Ohio. En línea: http://alternativas.osu.edu/es/issues/autumn-2013/debates/giunta.html (recuperado: 16-06-2017)

Narcisa Hirsch. Comp.: Sayago Victoria, Buenos Aires, Ed. MQ2*.

Marín, P. (2010) "La estructura presente. Narcisa Hirsch y el punto de quiebre del cine experimental en Argentina" en Narcisa. Catálogo de obra. Comp. Alejandra Torres, Buenos Aires, Casa Nacional del Bicentenario.

Paparella A. (1995), "Almuerzo en la hierba. Entrevista con Narcisa Hirsch sobre el cine experimental argentino", en Narcisa. Catálogo de obra. Comp. Alejandra Torres, Buenos Aires, Casa Nacional del Bicentenario.

Taquini, G. "Del mito de Narciso al mito de Proteo, un diálogo informal con Narcisa Hirsch", en Narcisa. Catálogo de obra. Comp. Alejandra Torres, Buenos Aires, Casa Nacional del Bicentenario.

Torres, A. (2010) "Ver (se) mirar a la cámara. Entrevista a Narcisa Hirsch" en Narcisa. Catálogo de obra. Comp. Alejandra Torres, Buenos Aires, Casa Nacional del Bicentenario.

Taquini, G. (2008) Video en Latinoamérica. Una historia crítica, Laura Baigorri (ed.) Brumaria n.10, AECID, Madrid.

Torres, A.; Garavelli, C. (2014) ¿Qué es lo experimental del cine y video experimental argentino?, IFOMAGIA $n^{\circ} 9$.

Textos Recuperados en Octubre y Noviembre de 2018 de http://www.bim.com.ar/

Textos Recuperados en Octubre y Noviembre de 2018 de http://asaeca.org/

Toro, K. (2012) "Marie Louise Alemann y el cine experimental argentino" en Ensayos sobre la Imagen. Edición XI. Año VIII, Vol. 48, Agosto 2012, Buenos Aires, Creación y Producción en Diseño y Comunicación №48. 
Abstract: this essay will investigate the leading role of female directors, programmers and curators of Argentine Experimental Cinema and Video Art.

Their material will be analyzed both, in the filmmaking of audiovisual work and in their roles of programmers of theaters, museums and cultural centers where space for the dissemination of Argentine experimental audiovisual has been devoted.

Several cases will be mentioned, though only historical periods of creation and consolidation of the experimental cinema and video art will be specifically analyzed.

In spite of multiple political and cultural contexts, activism among these female directors is a common factor as regards women rights within audiovisual business.

The names of prominent women in both cases are as follow: Marie-Louise Alemann, one of the pioneers of experimental cinema. She organized 'The Argentine Experimental Cinema Group' on the premises of the Goethe Institute and was in charge of the programming of this film archive between 1979 and 1985. This hub showed films by Rainer Werner Fassbinder, Alexander Kluge, Edgar Reitz or Wim Wenders.

Alemann was born in Germany in 1927 and settled down in Argentina in 1949. She was a photographer, journalist, stage actress, and painter. In 1967, when the Di Tella Institute of Arts was being fenced by the dictatorship of Juan Carlos Onganía, Alemann took part of a happening, together with Walter Mejia and Narcisa Hirsch, at the premiere of Blow Up, by Michelangelo Antonioni at the entrance of the theater hall. That art intervention in the thouroughfare was documented by filmmaker Raymundo Gleyzer. It was one of the few coincidences between aesthetic and political avant-gardes at that time.

Narcisa Hirsch, pioneer of experimental cinema, was part of the same group. "Cinema is just projected light, sheer movement" she vehemently maintained. From an interview (Paparella, 1995:34) Narcisa Hirsch, revisiting one of the basic premises of the Pictorical Modernism, proposed to focus in the very field of materials and cinema significance as a medium at its core. Experimental cinema presented its own essence, it built its object without any narrative intention or diegetic.

As for Video Art, in another historic and cultural context strongly associated with technological advancements and with the massiveness of video camera recorders, we will analyze the case of Graciela Taquini. In what refers to the figure of Graciela Taquini, we can say she has been, and still is, a key figure in the broadcasting and exhibition of Argentine Video Art. She is an Argentine artist and curator who has developed most of her artistic production in the area of the Monochannel Experimental Video. Her works have received different awards, among them Premio de la Asociación de Críticos de Arte de la Argentina (Argentina Arts Critics Association Award best script), Primer Premio del Festival Videobrasil (Video-Brazil Festival, first prize), and in 2005 Premio a la Acción Multimedia (Multimedia Action Award).Taquini has been nicknamed “The Aunt of Argentine Video Art” because of her early involvement and interest in that discipline. In 2012 she was awarded the Platinum Konex in Video Art. She is a permanent member at the Academia Nacional de Bellas Artes (National Accademy of Arts).

Finally, and in relation to the use of new media, a reflexion will take place about a group of female directors and cultural managers devoted to experimental cinema and video. The case of AREA (Experimental Audiovisual Filmmakers Association) will be mentioned. In 
spite of not being an exclusively female group, it counts with a Gender Commission where the women's issue in the experimental cinema and audiovisual is approached at length in a contemporary context.

Keywords: pioneering- experimental cinema - video art - filmmaking - cultural management - Goethe - technology - new media - feminisms

Resumo: O presente ensaio indagará sobre o papel protagónico de mulheres realizadoras, programadoras e curadoras de cinema experimental e video arte argentina. O trabalho será analisado tanto na realização de obra audiovisual como também em suas facetas de programadoras de salas, museus, centros culturais, que têm dedicado espaços à difusão do audiovisual experimental argentino.

Conquanto nomear-se-ão vários casos, analisar-se-ão pontualmente os momentos históricos de gestação e consolidação do cinema experimental e video arte em Argentina. Um ponto em comum, para além dos diversos contextos políticos e culturais, é o ativismo destas realizadoras em relação aos direitos das mulheres no meio audiovisual.

Os nomes e casos de mulheres proeminentes em ambos são os seguintes.

Marie-Louise Alemann, uma das pioneiras do cinema experimental, formou o "Grupo Cinema Experimental Argentino" na sede do instituto Goethe e esteve a cargo da programação da Cinemateca entre 1979 e 1985, espaço onde se podiam ver e debater os filmes de Rainer Werner Fassbinder, Alexander Kluge, Edgar Reitz ou Wim Wenders. Nasceu em Alemanha em 1927 e arraigou-se no país em 1949. Desempenhou-se como fotógrafa, jornalista, actriz teatral e artista plástica e para 1967 -quando a ditadura militar de Juan Carlos Onganía começava a cercar ao Instituto Dei Tella- participou junto a seus amigos Walter Mejía e Narcisa Hirsch de um happening na porta da sala onde se estreava Blow Up, de Michelangelo Antonioni. Aquela intervenção na via pública foi documentada por Raymundo Gleyzer, no que se considera foi uma das poucas coincidências entre o que eram então as vanguardas políticas e estéticas.

Narcisa Hirsch, pioneira do cinema experimental argentino, participou do mesmo grupo. O cinema "é só luz projectada, movimento puro" sustentava veementemente Narcisa Hirsch numa entrevista (Paparella, 1995: 34). Retomando uma das premisas básicas do modernismo pictórico. Hirsch propunha concentrar-se na própria esfera de materiais e significação do cinema como médio; em seu "esencia". O cinema experimental apresentava sua própria matéria, construía seu objeto sem nenhum tipo de intenção narrativa ou diegética. Pelo lado do videoarte, em outro contexto histórico e cultural, fortemente unido aos avanços técnicos e à masividade das câmaras gravadores de video, analisaremos o caso de Graciela Taquini. Em relação à figura de Graciela Taquini, pode-se mencionar que tem sido e continua o sendo até hoje, uma figura finque na difusão e exibição do video arte argentina. É uma artista e curadora argentina que tem desenvolvido a maior parte de sua produção artística no área do video experimental monocanal. Suas obras têm recebido diferentes prêmios, entre eles o Prêmio da Associação de Críticos de Arte da Argentina ao melhor guion, o Primeiro Prêmio do Festival Videobrasil, e em 2005 o Prêmio à Acção Multi- 
média, Associação Argentina de Críticos de Arte. Tem sido apodada "a tia do videoarte argentino" por sua temporã participação e interesse em dita disciplina. Em 2012 recebeu a Prêmio Konex de Platino em Video Arte. É membro de número da Academia Nacional de Belas Artes.

Finalmente, e em relação ao uso dos novos meios, reflexiona-se sobre um grupo de mulheres realizadoras e gestoras culturais dedicadas ao cinema e video experimental, mencionando o caso de AREA Associação de realizadores experimentais audiovisuais. Conquanto não é um grupo exclusivamente feminino, conta com uma comissão de género no que a problemática da mulher no cinema e no audiovisual experimental é amplamente abordado, num contexto contemporâneo.

Palavras chave: pioneiros - cinema experimental - videoarte - realização - gestão cultural - Goethe - tecnologia - novas mídias - feminismos.

[Las traducciones de los abstracts fueron supervisadas por el autor de cada artículo] 